\title{
Analytical and experimental determination of radiation and temperature distributions inside solar receivers
}

\author{
C. Haziza and D. Blay \\ Laboratoire d'Energétique Solaire, 40, avenue du Recteur Pineau, 86022 Poitiers Cedex, France \\ (Reçu le 11 juillet 1979, révisé le 29 octobre 1979, accepté le 31 octobre 1979)
}

\begin{abstract}
Résumé. - Ce papier présente la modélisation d'un récepteur solaire cubique recevant un flux solaire concentré non uniforme. On utilise les hypothèses des surfaces diffuses et grises par bandes et la méthode des radiosités. Deux équations supplémentaires correspondant au transfert de la chaleur à un fluide caloporteur permettent de définir l'équilibre thermique. On détermine dans ces conditions les répartitions des flux nets et des températures à l'intérieur de la cavité. De plus, une chaudière solaire cubique a été réalisée et installée au foyer d'un four solaire d'une puissance de $6 \mathrm{~kW}$. Les flux et les températures ont été mesurés pour différents états de surface de la cavité. Les résultats théoriques et expérimentaux ont ensuite été comparés et discutés.
\end{abstract}

Abstract. - A cooled cubic cavity receiving a non uniform concentrated solar radiation is modelized, using the diffuse and semi-gray surface hypothesis and the net radiation method equations. Two more equations corresponding to the heat transfer to a cooling fluid permit to define a heat balance. Thus at thermal equilibrium, net fluxes and temperatures inside the cavity are calculated. An air-cooled solar receiver has been set up at a $6 \mathrm{~kW}$ solar furnace. Flux and temperature measurements have been performed for different coatings of the inside surface. Theoritical and experimental results are then compared and discussed.

\section{Nomenclature}

$A$

$C$

e

$k$

$h$

$F_{i j}$

$N$

$T_{f}$

$T_{0}$

$T_{w}$

$q$

$\alpha_{I R}\left(=\varepsilon_{I R}\right)$

$\alpha_{s}$

$\eta$

$\varepsilon_{\mathrm{RR}}$

$\lambda$

$\sigma$
Area of a surface element.

Specific heat.

Wall thickness.

Forced convection heat transfer coefficient.

Natural convection heat transfer coef-

ficient.

Shape factor relating elements $i$ and $j$.

Radiosity.

Total number of surface elements.

Fluid temperature.

Ambient temperature.

Wall temperature.

Flowrate.

Surface absorptance for thermal infra-red radiation.

Surface absorptance for solar radiation.

Theoretical thermal efficiency of the cavity.

Surface hemispherical emittance for thermal infra-red radiation.

Thermal conductivity of the walls.

Stefan-Boltzmann constant. $\varphi_{s} \quad$ Incident solar flux density.

$\varphi_{\text {Rad }} \quad$ Net radiative flux density.

$\Phi_{\text {Net }}$. Net flux.

()$_{i \text { or } j}$ Relating to surface element $i$ or $j$.

()$_{s} \quad$ Relating to solar energy.

( ) Relating to infra-red radiation.

1. Introduction. - Many studies are now undertaken in order to design and build cavities to collect concentrated solar energy and to transform it into heat at different temperature levels.

Numerous theoretical papers deal with the problem of flux redistribution in different shape enclosures, but, in most of them, only infrared thermal radiation is considered. However Bobco [1] and Plamendon [2] have been studying this problem for two particular cases, respectively a cylindrical and a dihedral cavity, submitted to a uniform solar flux.

The originality of our paper is to present in addition to a mathematical model for the determination of net flux and temperature distribution inside a cooled cubic solar receiver, experimental results which are compared to theoretical ones. 
2. Theoretical study. -2.1 Definition of THE PROBLEM. - The purpose here is to calculate the thermal equilibrium of the cavity, taking in account the different heat transfer processes described as follows :

- Radiant heat transfer. Two types of radiation are concerned. First, solar radiation in the spectral band $|0-2 \mu|$ and second, infrared radiation diffusely given off by the inner surface of the enclosure $|>2 \mu|$. In both cases, multireflections are considered.

- Heat transfer by radial conduction through the walls of the receiver (longitudinal conduction is neglected). flow.

- Heat transfer by forced convection to the fluid

- Heat transfer by natural convection of the air outside the cavity.

The last three heat transfer modes are assumed to be known and hence are characterized by appropriate coefficients. The analysis which uses a zone method is based on the following hypothesis :

a) The surfaces of the enclosure are considered to be both diffuse and semi-gray.

b) The solar absorptance and the emittance of the surfaces, as well as the thermal properties of the walls and fluid, are assumed to be independant of temperature.

c) The cavity is divided in identical surface elements sufficiently small, so that each of them may be considered as isothermal and receiving a uniform flux.

2.2 Equations. - The equations governing the radiative exchange inside the enclosure are established by using the net-radiation method (the radiosity concept) $[1,2]$. Solar and infra-red radiosities from an element $j$ can be written :

$$
\begin{aligned}
& J_{s, j}=\left(1-\alpha_{s, j}\right)\left[\varphi_{s, j}+\sum_{i=1}^{N} J_{s, l} F_{j i}\right] \\
& J_{\mathrm{IR}, j}=\left(1-\alpha_{\mathrm{IR}, j}\right)\left[\sum_{i=1}^{N} J_{\mathrm{IR}, i} F_{j i}\right]+\varepsilon_{\mathrm{IR}, i} \sigma T_{w, j}^{4}
\end{aligned}
$$

so, the net radiative flux available on a surface element $i$ is :

$$
\begin{aligned}
\varphi_{\mathrm{Rad}, i}=\alpha_{s, i}\left[\varphi_{\mathrm{s}, i}\right. & \left.+\sum_{j=1}^{N} J_{\mathrm{s}, j} F_{i j}\right]+ \\
& +\alpha_{\mathrm{IR}, \imath}\left[\sum_{j=1}^{N} J_{\mathrm{IR}, j} F_{i j}\right]-\varepsilon_{\mathrm{IR}, i} \sigma T_{w, i}^{4} .
\end{aligned}
$$

If one considers natural convection inside the cavity, the net flux available just given becomes :

$$
\Phi_{\mathrm{Net}, i}=\left[\varphi_{\mathrm{Rad}, i}-h_{i}\left(T_{w, i}-T_{0}\right)\right] A_{i} .
$$

At thermal equilibrium, two more relations concerning the zones $i$ and $i-1$ can be added :

$$
\begin{aligned}
\Phi_{\mathrm{Net}, i} & =q C_{i}\left(T_{f, i}-T_{f, \iota-1}\right) \\
\Phi_{\mathrm{Net}, i} & =K_{\iota}\left[T_{w, \imath}-\frac{1}{2}\left(T_{f, \iota}+T_{f, \iota-1}\right)\right] A_{i}
\end{aligned}
$$

where

$$
\frac{1}{K_{i}}=\frac{1}{k_{i}}+\frac{e}{\lambda} .
$$

This system of eqs. (1), (2), (3) and (4) is solved on an IBM 370 computer by using the classical matrix inversion pivot method. The coupling between radiosities and wall temperatures is treated by an iterative method where the initial values of the wall temperatures are those obtained when considering the problem without infra-red radiation. In this case, very few iterations are needed.

A maximum number of zones of 125 has been chosen considering the computational time necessary to solve the system.

So, net fluxes, wall and fluid temperatures are calculated for different values of the parameters in the case of a cubic cavity. Furthermore, the thermal efficiency of the cavity, $\eta$, is determined as :

$$
\eta=\frac{\sum_{\iota} \varphi_{s, i} A_{\iota}}{\sum_{\iota} \Phi_{\mathrm{Net}, i}} .
$$

3. Experiments. - 3.1 EXPERIMENTAL TEST SET UP. - To test the validity of the model, a cubic cavity with side measuring $0.3 \mathrm{~m}$, opened on an entire side, has been built. The remaining faces which are made of steel plates $0.8 \mathrm{~mm}$ thick are air-cooled and well insulated. The air flow assured by a compressor is directed by a set of baffle-plates (Fig. 1). Flow rate is obtained by a D.P. Cell flowmeter.

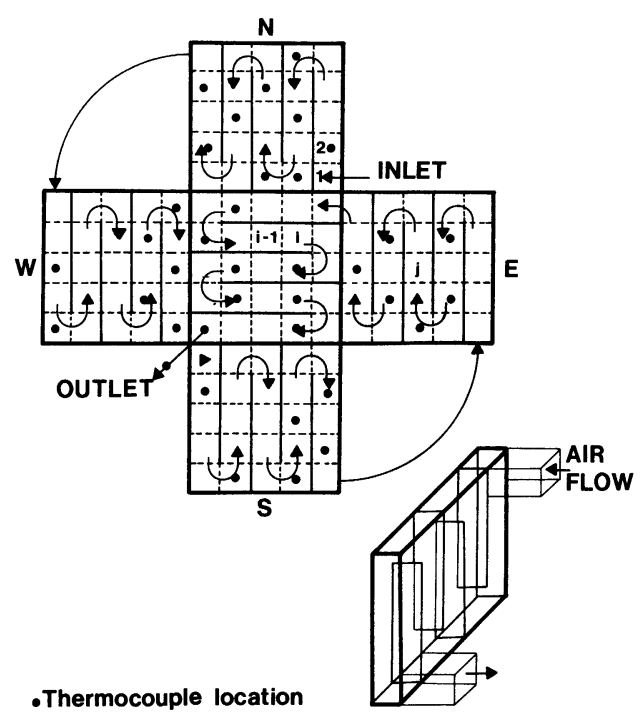

Fig. 1. - Developed view of the cavity. Perspective view of one side showing baffle-plates directing the air flow. 
The cavity has been set up at the $6 \mathrm{~kW}$ solar furnace of the Laboratoire d'Energétique Solaire facilities at Odeillo (France).

This device comprises a $45 \mathrm{~m}^{2}$ heliostat which tracks the sun and a concentrating parabolic mirror (4 $\mathrm{m}$ diameter and $4 \mathrm{~m}$ focal length) composed of 300 focusing facets.

The inside surface of the cavity has been partitioned into 125 elements. Temperature measurements have been made from 35 wall and 35 fluid thermocouples located as shown on figure 1 . Their indications have been recorded on a data acquisition system.

\subsection{Preliminary experiments. - Before starting} the tests, it was necessary to determine the different parameters values : $\varphi_{s}, \alpha_{s}, \varepsilon_{\mathrm{IR}}, k, h$.

The incident solar fluxes, $\varphi_{s, i}$, have been measured during a period with constant solar beam radiation by means of a photocell located inside an integrating sphere and confirmed by a calibrated gardon type fluxmeter. Results are shown on figure 2, they correspond to a standard solar beam radiation of $1000 \mathrm{~W} / \mathrm{m}^{2}$.

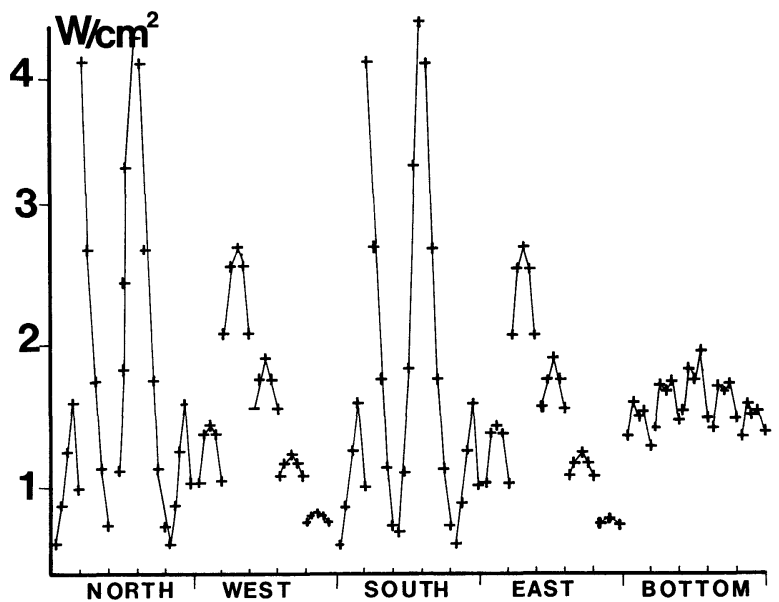

Fig. 2. - The incident solar flux density on the 125 surface elements of the cavity along the air flow path.

The absorptance $\alpha_{s}$ and emittance, $\varepsilon_{\mathrm{IR}}$, of the different coatings used have been evaluated by the thin skin calorimeter technique.

The forced convection heat transfer coefficients, $k_{i}$, were measured directly from a black smoked cooled panel identical to those constituting the cavity. Depending on the position considered inside the panel, these coefficients vary from 136 to $160 \mathrm{~W} / \mathrm{m}^{2}{ }^{\circ} \mathrm{C}$ for a flow rate of $0.022 \mathrm{~kg} / \mathrm{s}$.

Till now, no results concerning the three-dimensional free convection inside opened cavities are available. So, the values calculated by F. Penot [4] in the two-dimensional case have been used. Owing to the fact that the free convection heat transfer coefficients are small compared with forced convection and radiative ones $\left(2.7<h_{i}<3.5 \mathrm{~W} / \mathrm{m}^{2}{ }^{\circ} \mathrm{C}\right)$, it has been considered that this approximation affect very little the solutions.

3.3 Tests AND Results. - Tests have been carried out for different flowrates and surface conditions : the steel walls were successively black-smoked, whitepainted, a combination of black-smoked and whitepainted and finally polished. In each case, under steady state conditions, temperatures, flowrate and solar beam radiation have been measured.

Now, referring to eq. (4), we present the results in term of the temperature difference

$$
T_{w}-T_{f}=\left(T_{w, i}-\frac{1}{2}\left(T_{f, i}+T_{f, i-1}\right)\right)
$$

to which the net flux, $\Phi_{\mathrm{Net}, i}$, is directly proportional. Numerical, and experimental results are compared in figures $3,4,5$ and 6.

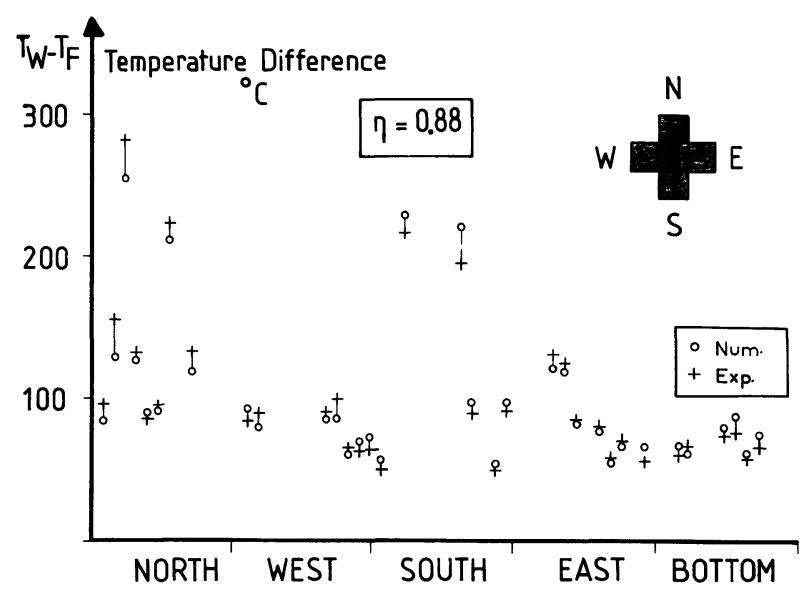

Fig. 3. - Temperature difference between wall and fluid. Black coating : $\alpha_{\mathrm{s}}=0.98, \quad \varepsilon_{\mathrm{IR}}=0.98, q=0.022 \mathrm{~kg} / \mathrm{s}, \quad T_{\text {inlet }}=3.8^{\circ} \mathrm{C}$, $T_{\text {outlet }}=295^{\circ} \mathrm{C}$.

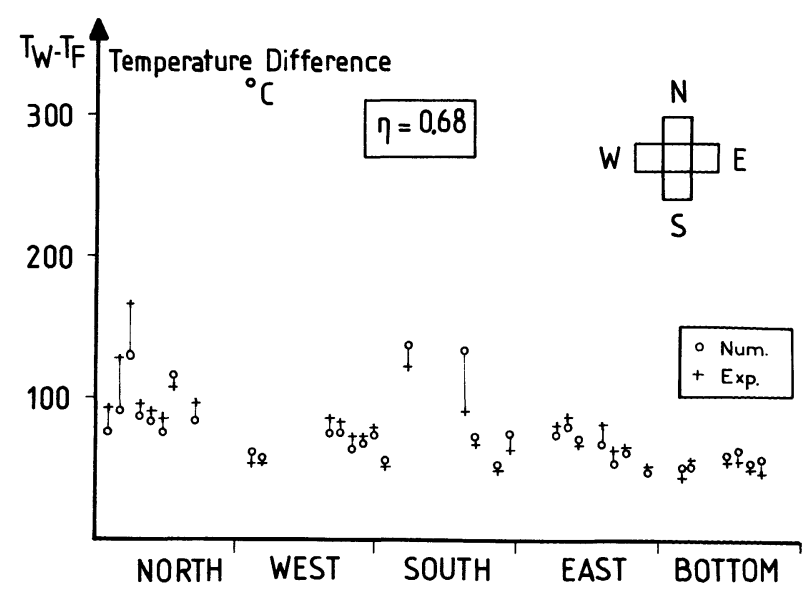

Fig. 4. - Temperature difference between wall and fluid. White coating : $\alpha_{s}=0.37, \varepsilon_{\mathrm{IR}}=0.92, q=0.022 \mathrm{~kg} / \mathrm{s}, T_{\text {inlet }}=3.8^{\circ} \mathrm{C}$, $T_{\text {oullet }}=227^{\circ} \mathrm{C}$. 


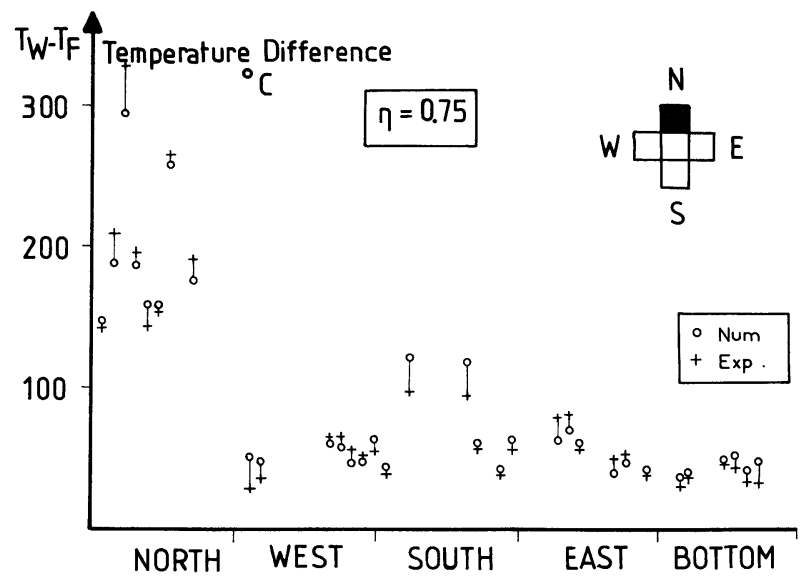

Fig. 5. - Temperature difference between wall and fluid. North side black : $\alpha_{s}=0.98, \varepsilon_{\mathrm{IR}}=0.98$. Other sides white : $\alpha_{s}=0.37$, $\varepsilon_{\mathrm{iR}}=0.92, q=0.022 \mathrm{~kg} / \mathrm{s}, T_{\text {inlet }}=5.3^{\circ} \mathrm{C}, T_{\text {oullet }}=250^{\circ} \mathrm{C}$.

3.4 Discussion. - In two cases, that of the blacksmoked (Fig. 3) and white-painted walls (Fig. 4), the results nearly coincide; except in zones of highly non uniform flux (i.e. on the north and south sides) where hypothesis (c) mentioned above is not satisfied. Also, in these zones, longitudinal conduction is no longer negligible.

For the two-colour cavity (Fig. 5), the same remarks can be made.

At the contrary when the steel walls of the enclosure are polished (Fig. 6), the discrepancy becomes more important. It can be noted that measured temperatures are higher than the calculated ones on the bottom of the cavity and lower on the other sides.

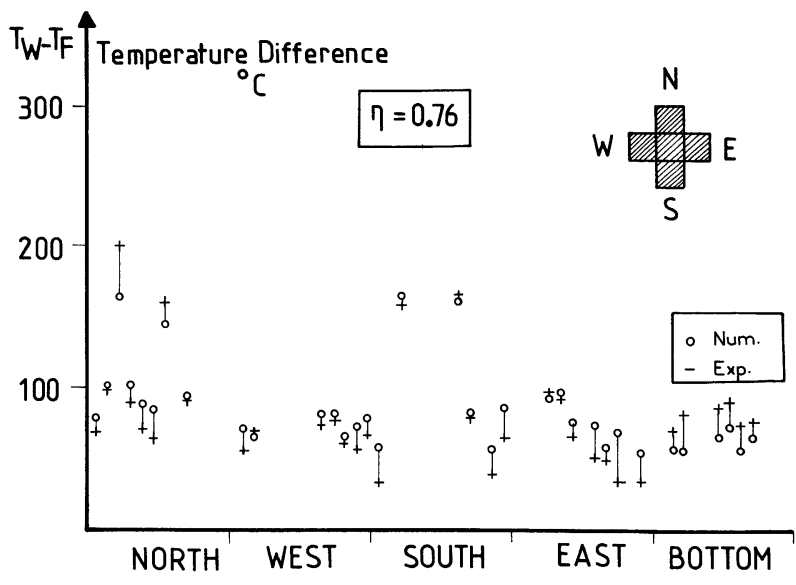

Fig. 6. - Temperature difference between wall and fluid. Polished steel walls : $\alpha_{\mathrm{s}}=0.52, \varepsilon_{\mathrm{lR}}=0.20, q=0.022 \mathrm{~kg} / \mathrm{s}, T_{\text {inlet }}=3.8^{\circ} \mathrm{C}$, $T_{\text {outa }}=243.8^{\circ} \mathrm{C}$

This is due to the relatively important part of specular reflections on the polished surface which have been neglected in the theoretical study.

4. Conclusions. - These results demonstrate the validity of the model when incident flux is sufficiently uniform and does not generate large temperature gradients along the surface. If surfaces do not present a rate of specular reflections which is too high, accurate results can be obtained when this theory is applied to usual real surfaces, but they could be appreciably improved when taking in account longitudinal conduction inside the walls.

\section{References}

[1] Bobco, R. P., Allen, G. E., Othmer, P. W., Local Radiation Equilibrium Temperatures in Semigray Enclosures. $J$. Spacecr. 4, no 8 (1967) 1076-1082.

[2] Plamondon, J. A., Landram, C. S., Radiant heat transfer from nongray surfaces with external radiation. A.I.AA Prog. Astronaut. Aeronaut. (Academic Press, INC. N.Y.) 18 (1966) 173-197.

[3] Siegel, R., Howell, J. R., Thermal Radiation heat Transfer (International Student Edition) Mac Graw Hill, Kogakusha Ltd.

[4] Penot, F.; Two-dimensional free convection inside opened cavities. U.S. French Symposium on convection losses of receivers for solar power plants. 17th-18th april 1978. Pirdes, 282 boulevard St-Germain, 75007 Paris, France.
[5] Bernard, J., Contribution à l'étude des cavités rayonnantes et des chaudières solaires. Thèse de Docteur-Ingénieur, Poitiers, France, Déc. 1977.

[6] JARVinen, P. O., Solar heated air receiver. Sol. Energy, Vol. 19, 139-143.

[7] GinTz, J., Closed cycle, high temperature central receiver concept for solar electric power station. Boeing engineering and construction, EPRI (1978). 